\title{
AIRFOIL TYPES EFFECT ON GEOMETRY AND PERFORMANCE OF A SMALL-SCALE WIND TURBINE BLADE DESIGN
}

\author{
Sigit Iswahyudi $i^{1,}{ }^{\star}$, Sutrisno ${ }^{1}$, Prajitno $^{1}$, Setyawan Bekti Wibowo ${ }^{3}$ \\ ${ }^{1}$ Department of Mechanical and Industrial Engineering, Universitas Gadjah Mada, Indonesia \\ ${ }^{2}$ Department of Mechanical Engineering, Universitas Tidar, Indonesia \\ ${ }^{3}$ Department of Mechanical Engineering, Vocational School, Universitas Gadjah Mada, Indonesia
}

\begin{abstract}
Many airfoils could be used to form a wind turbine blade. Different airfoil would result in an altered blade planform and its performance characteristics. Airfoil identification that should be included in the design then becomes an important task. Utilizing Blade Element Momentum Theory computation procedures, eleven types of airfoils were applied in blade geometries of rotors of $2.4 \mathrm{~m}$ in diameters. The changes in the distribution of chord lengths, twists, solidity ratio, and Reynolds numbers of the blades were compared as geometry parameters. The designed and off designed powers and thrusts were calculated, and the characteristics of the performance of the rotor were represented by the coefficient of power and coefficient of thrust. The calculated geometries showed that distinct airfoils resulted in different segments sizes of the blades and different performance characteristics of the rotors. The use of an airfoil that has a high lift coefficient and a high glide ratio in the design of a blade will produce a narrow blade and a small solidity ratio. The design will also have a high power coefficient at the tip speed ratio design. However, the blade power coefficient may be sensitive to changes in rotational speed.
\end{abstract}

Key words: small-scale HAWT, airfoil, blade geometry, rotor performance, BEM

\section{INTRODUCTION}

Researchers have been striven to raise the aerodynamic performance of wind turbines. They have been modified the used airfoil, the designed planform, and the designed system attached or around turbines. A new type of airfoil series has been developed and succeeded in increasing the power coefficient power, annual energy production, and lowering root load [1][2]. The planform of a small wind turbine has been modified from straight design to curved one [3][4] and from simple tip geometry to a tip added with swept, winglet, dihedral or anhedral [5]-[7]. By adding a diffuser at a wind turbine rotor system, the performances were significantly increased [4][8]. A pitch control has been attached in the rotor systems to optimize harvesting power from a range of wind speeds [9]-[11].

A blade of a wind turbine rotor could consist of one or several types of airfoils. The designer might choose some of them to reach the optimum aerodynamics behavior and mechanical strength for rating operation. The choice of the airfoil for blade design is related to its aerodynamic characteristics. The lift and drag coefficient characteristics determine the glide airfoil ratio associated with the efficiency of the profile. The blade is designed at an airfoil angle of attack where the maximum glide ratio. The higher the glide ratio, the more efficient the blade profile. Meanwhile, the airfoil geometry in the blade design determines the centrifugal force and blade strength when the turbine is operated. Small wind turbine rotor blades usually consist of one type of airfoil. Thin airfoil can be used to save material, reduce weight and facilitate balancing. In the case of large-scale blade designs, several airfoils can be used simultaneously to meet the aerodynamic and structural strength requirements. Thin airfoil is used at the tip of the blade while thick airfoil is used at the root. Some researches show the optimum blade design [12] to [14], but the reason why the airfoils used in the works are selected from the others need extended explanation. Different types of airfoil might give different optimum blade planform and performance. The need for wind turbine blade design was relayed primarily on two-dimensional aerodynamic characteristics of a used airfoil. For low Reynolds number, the chosen airfoil should have a maximum thickness as small as possible, and the location of the relative thickness located close to trailing edge as it had good performance [15]. However, reviewing airfoil properties by looking for the angle of attack at maximum glide ratio might be more accessible. The design of the angle of attack would result in the end properties of the blade design [16]. By the fast and familiar method, BEMT, parameters needed from an airfoil for blade design are angle of attack of the design, coefficient of lift at an angle of attack of design, characteristic of the coefficient of lift as a function of angle of attack, and coefficient of drag as a function of angle of attack. The parameters were used to acquire the blade geometry and to determine the performance [17]-[19].

To know how airfoils affect the blades geometry and their performance, in the current paper, eleven blades that are designed by BEMT with different airfoils for each blade that usually used in researches and constructions will be discussed. BEM based computing method was selected for blades design in this paper since it was simple, fast calculating, had proven good accuracy [20]-[22], and not sensitive to the thickness of airfoil as blade design using this method only required information on the value of the lift and drag coefficient, not airfoil geometry. 


\section{MATERIALS AND METHODS}

\section{Airfoils}

The design process using BEM utilizes the two-dimensional aerodynamic characteristics of the airfoil. The polynomial equation is used to approach the lift and drag coefficient values as close as possible. The first-order approach can be carried out in an area where changes in the airfoil angle of attack give a linear change to the lift and drag coefficients. Meanwhile, the second-order curve can be used in a change in the angle of attack which results in a parabolic change in the lift and drag coefficients. The choice of the order of the curve to approach the aerodynamic characteristics of an airfoil depends on the ability of the curve to approach the characteristics of the airfoil. Here, the 4th order polynomial has been chosen to approach the characteristics of an airfoil in all parts of the angle of attack. Blades cross cross-sec- tions of each HAWT rotor in this paper were built utilizing one of the airfoils mentioned in Table 1. All data in Table 1 were based on airfoil characteristics with Reynolds number 200000 . The sections' shapes were used commonly in wind turbine rotor developments. Coefficients of lift $\left(C_{L}\right)$ and coefficients of drag $\left(C_{D}\right)$ data were extracted from http://airfoiltools.com. The page uses Xfoil to design and analyze subsonic airfoils. The application uses the high order panel method combined with viscous/inviscid interactions. The data then were approximated by polynomial fits of order four as in Eq. 1. The equations arefunctions of the angle of attack of an airfoil ( $\alpha$ ) that have constants a1, a2, a3, a4, and a5. The lift coefficients for design $\left(\mathrm{C}_{\mathrm{L}, \mathrm{D}}\right)$ in the third column in the table were determined at a design angle of attack $\left(\alpha_{D}\right)$ where the ratio of lift to drag reached a maximum $\left(\left(C_{L} C_{D}\right)_{\max }\right)$.

$$
C_{\text {Lor } D}=a 1 \alpha^{4}+a 2 \alpha^{3}+a 3 \alpha^{2}+a 4 \alpha+a 5
$$

Table 1: Blade cross-section airfoils

\begin{tabular}{|c|c|c|c|c|c|c|}
\hline Airfoils & $\begin{array}{c}\left(C_{L} / C_{D}\right) \\
\left.\max ^{*}\right)\end{array}$ & $C_{L, D}$ & $\begin{array}{l}\alpha_{D} \\
\left({ }^{*}\right)^{*}\end{array}$ & $\begin{array}{l}\alpha_{\text {st }} \\
\left.\left({ }^{0}\right)^{*}\right)\end{array}$ & $\begin{array}{l}\text { Polinomial Constants for } \\
C_{L}(a 1, a 2, a 3, a 4, a 5)^{*}\end{array}$ & $\begin{array}{l}\text { Polinomial Constants for } \\
C_{D}(a 1, a 2, a 3, a 4, a 5)^{*}\end{array}$ \\
\hline $\begin{array}{c}\mathrm{AH} 93-\mathrm{W}-300 \\
{[23]}\end{array}$ & 42.24 & 1.19 & 8.50 & 17.25 & $\begin{array}{l}\text { 8.36E-06, -3.03E-04, } \\
-8.50, \text { E-04, 1.23E-01 }\end{array}$ & $\begin{array}{l}-7.49 \mathrm{E}-07,4.58 \mathrm{E}-05 \\
-4.3 \mathrm{E}-04,1.58 \mathrm{E}-03\end{array}$ \\
\hline NACA 0012 [24] & 47.43 & 0.62 & 5.00 & 12.25 & $\begin{array}{c}-1.49 \mathrm{E}-04,3.96 \mathrm{E}-03 \\
-3.84 \mathrm{E}-02,2.42 \mathrm{E}-01 \\
-394 \mathrm{E}-02\end{array}$ & $\begin{array}{c}\text { 6.12E-06, -1.26E-04, } \\
\text { 1.07E-03, -2.51E-03, } \\
1.15 \mathrm{E}-02\end{array}$ \\
\hline NACA-0015 [25] & 49.63 & 0.78 & 6.25 & 14.25 & $\begin{array}{c}-5.20 \mathrm{E}-05,1.62 \mathrm{E}-03 \\
-2.16 \mathrm{E}-02,2.16 \mathrm{E}-01 \\
-7.58 \mathrm{E}-02\end{array}$ & $\begin{array}{c}\text { 8.02E-06, -2.13E-04, } \\
1.94 \mathrm{E}-03,-5.15 \mathrm{E}-03 \\
1.41 \mathrm{E}-02\end{array}$ \\
\hline NACA0018 [26] & 50.05 & 0.92 & 7.00 & 17.25 & $\begin{array}{c}2.48 \mathrm{E}-05,-8.53 \mathrm{E}-04 \\
3.93 \mathrm{E}-03,1.30 \mathrm{E}-01 \\
-3.87 \mathrm{E}-02 \\
\end{array}$ & $\begin{array}{c}2.14 \mathrm{E}-06,-5.21 \mathrm{E}-05 \\
4.97 \mathrm{E}-04,-8.00 \mathrm{E}-04 \\
1.25 \mathrm{E}-02 \\
\end{array}$ \\
\hline NACA23012 [18] & 50.98 & 1.08 & 9.00 & 13.50 & $\begin{array}{c}-6.51 \mathrm{E}-06,-6.32 \mathrm{E}-05 \\
5.15 \mathrm{E}-04,1.00 \mathrm{E}-01 \\
2.30 \mathrm{E}-01 \\
\end{array}$ & $\begin{array}{c}\text { 4.20E-06, -9.66E-05, } \\
\text { 7.75E-04, -1.15E-03, } \\
1.11 \mathrm{E}-02\end{array}$ \\
\hline S809 [27] & 51.73 & 0.99 & 8.25 & 15.75 & $\begin{array}{c}2.39 \mathrm{E}-05,9.39 \mathrm{E}-4 \\
7.68 \mathrm{E}-03,6.87 \mathrm{E}-02 \\
2.04 \mathrm{E}-01 \\
\end{array}$ & $\begin{array}{c}\text { 3.10E-06, -7.16E-05, } \\
9.09 \mathrm{E}-04,-5.83 \mathrm{E}-03, \\
3.96 \mathrm{E}-02\end{array}$ \\
\hline S1046 [4] & 55.02 & 0.93 & 8.00 & 13 & $\begin{array}{c}5.15 \mathrm{e}-05,2.10 \mathrm{E}-03 \\
2.20 \mathrm{E}-02,3.84 \mathrm{E}-02 \\
3.94 \mathrm{E}-02\end{array}$ & $\begin{array}{c}2.07 \mathrm{E}-06,-2.76 \mathrm{E}- \\
05,1.29 \mathrm{E}-04 \\
2.02 \mathrm{E}-04,1.25 \mathrm{E}-02\end{array}$ \\
\hline NACA4418 [28] & 67.02 & 1.24 & 7.50 & 14.25 & $\begin{array}{c}-3.45 \mathrm{E}-06,1.38 \mathrm{E}-04 \\
-6.80 \mathrm{E}-03,1.50 \mathrm{E}-01 \\
4.48 \mathrm{E}-01 \\
\end{array}$ & $\begin{array}{c}8.26 \mathrm{E}-07,4.59 \mathrm{E}-06, \\
-1.60 \mathrm{E}-04,1.37 \mathrm{E}-03, \\
1.19 \mathrm{E}-02 \\
\end{array}$ \\
\hline S822 [3] & 68.56 & 0.99 & 7.00 & 15.5 & $\begin{array}{c}-9.05 \mathrm{E}-06,3.58 \mathrm{E}-04, \\
-1.00 \mathrm{E}-02,1.73 \mathrm{E}-01, \\
2.36 \mathrm{E}-02 \\
\end{array}$ & $\begin{array}{c}4.15 \mathrm{E}-06,-1.08 \mathrm{E}-04, \\
1.21 \mathrm{E}-03,-5.56 \mathrm{E}-03, \\
2.52 \mathrm{E}-02 \\
\end{array}$ \\
\hline NACA 63-418 [4] & 69.31 & 1.21 & 9.25 & 17.25 & $\begin{array}{c}\text { 6.43E-05, 2.03E-03, } \\
\text { 1.45E-02, 8.06E-02, } \\
3.29 \mathrm{E}-01 \\
\end{array}$ & $\begin{array}{c}\text {-5.37E-06, 2.00E-04, } \\
-1.95 \mathrm{E}-03,6.06 \mathrm{E}-03, \\
1.25 \mathrm{E}-02 \\
\end{array}$ \\
\hline NACA 4412 [29] & 78.14 & 1.20 & 7.00 & 15.25 & $\begin{array}{c}\text { 3.03E-05, 9.60E-04, } \\
\text { 4.89E-03, 1.02E-01, } \\
4.89 \mathrm{E}-01\end{array}$ & $\begin{array}{c}-1.09 \mathrm{E}-06,5.43 \mathrm{E}-05 \\
4.30 \mathrm{E}-04,1.58 \mathrm{E}-03 \\
9.51 \mathrm{E}-03\end{array}$ \\
\hline
\end{tabular}

* The data were extracted from http://airfoiltools.com 


\section{Blade Element Method (BEM)}

BEM based computation procedures were the workhorse in forming blades geometries and analyzing rotors characteristics. The methods have been presented in some references, i.e., by Schaffarczyk [17], Gundtoft [18], and Burton et al. [19]. In this paper, we discussed rotors that consisted of three blades $(B)$, radius $(R)$ of 1.2 $\mathrm{m}$ and tip speed ratio of the design $\left(\lambda_{D}\right)$ equalss 8 . The tip speed ratio was the ratio between tangential speed of blade tip and wind speed on operated designs. The rotors had rated rotation speed of about $700 \mathrm{rpm}$ which were matched with generator rated speed operation. Chords $(c)$ and twists $(\beta)$ distributions of the blades were calculated based on optimum Schmitz blade geometries as in Eq. 2 and 3. The coefficient of lift and drag characteristic of airfoils were approximated using Reynolds numbers (Eq. 4) of each blade segment when operated at wind speed $10 \mathrm{~m} \cdot \mathrm{s}^{-1}$ and air condition at $25^{\circ} \mathrm{C}$. The Reynolds numbers were calculated based on relative wind speed $\left(\mathrm{V}_{\text {rel }}\right.$, Eq. 5 and 6$)$ at an angle of $\varphi$ with axial interference values $(a)$ determined at optimum at $1 / 3$. The angle of attacks $\left(\alpha_{D}\right)$ and coefficients of lift $\left(C_{\mathrm{LDD}}\right)$ of the designs then were defined at the maximum glide ratio $\left(\left(C_{L} / C_{D}\right)_{\text {max }}\right)$ of related airfoils characteristic. Small wind turbines are recommended to be placed in an area that is not affordable by the electricity network but has a large wind resource potential. The choice of wind speed of $10 \mathrm{~m} / \mathrm{s}^{-1}$ here may be somewhat excessive because the nominal value is rarely encountered. Small wind turbines will receive energy from winds whose speeds vary due to their relatively low placement from the ground. This wind speed may be found in narrow valley areas that form the aisles or in coastal areas that have a certain landform.

$$
\begin{aligned}
& c(r)=\frac{1}{B} \frac{16 \pi r}{C_{L, D}} \sin ^{2}\left(\frac{1}{3} \arctan \left(\frac{R}{\lambda_{D} r}\right)\right) \\
& \beta(r)=\frac{2}{3} \arctan \frac{R}{\lambda_{D} r}-\alpha_{D} \\
& R e(r)=\frac{\rho V_{r e l}(r) c(r)}{v} \\
& \varphi(r)=\frac{2}{3} \arctan \frac{R}{\lambda_{D} r} \\
& V_{r e l}(r)=\frac{(1-a) V_{\infty}}{\sin \varphi(r)}, \quad a=\frac{1}{3}
\end{aligned}
$$

Performances of the rotors were computed by iterating the axial (a) and tangential (a') interference. The values were started from zero then calculated by Eq. 7- 13 iteratively until their error reaches under 0.001. Prandtl tip loss correction was used in rotor performance calculations. The tip loss factor $F$ in Equation 11 was involved in

$$
a=\left\{\begin{array}{cc}
\frac{1}{\frac{4 F \sin ^{2}(\varphi)}{\sigma c_{y}}+1}, & a \leq 0.2 \\
\frac{1}{2}\left(2+K\left(1-2 a_{c}\right)-\sqrt{\left(K\left(1-2 a_{c}\right)+2\right)^{2}+4\left(K a_{c}^{2}-1\right)}\right) & , a>0.2, a_{c}=0.2
\end{array}\right.
$$

iterations to correct the values of axial interference (Eq. 7) and tangential interference (Eq. 8). The axial force (T) of the rotors were was the sum of axial forces of blade segments (Eq. 14), and the powers $(P)$ were results from the generated power of all blade segments (Eq. 15). The performances were presented in the coefficient of power $\left(C_{P}\right)$ and thrust $\left(C_{T}\right) \cdot C_{P}$ was defined as the ratio of power produced by wind turbine rotors to the wind flow (Eq. 16) and $\mathrm{C}_{\mathrm{T}}$ was calculated as the ratio of the axial force of the rotors to wind thrust (Eq. 17).

$$
a^{\prime}=\frac{1}{\frac{4 F \sin (\varphi) \cos (\varphi)}{\sigma C_{x}}-1}
$$

$F=\frac{2}{\pi} \arccos \left(\exp \left(-\frac{B}{2} \frac{R-r}{r \sin (\varphi)}\right)\right)$

$\sigma=\frac{c B}{2 \pi r}$

$K=\frac{4 F \sin ^{2}(\varphi)}{\sigma C_{y}}$

$\mathrm{C}_{\mathrm{y}}=\mathrm{C}_{\mathrm{L}} \cos (\varphi)+\mathrm{C}_{\mathrm{D}} \sin (\varphi)$

$\mathrm{C}_{\mathrm{x}}=\mathrm{C}_{\mathrm{L}} \sin (\varphi)-\mathrm{C}_{\mathrm{D}} \cos (\varphi)$

$T=B \int_{0}^{R} \frac{1}{2} \rho w^{2} c C_{y} d r$

$P=\omega B \int_{0}^{R} \frac{1}{2} \rho w^{2} c C_{x} r d r$

$C_{P}=\frac{P}{\frac{1}{2} \rho V_{\infty}^{3} A}$

$C_{T}=\frac{T}{\frac{1}{2} \rho V_{\infty}^{2} A}$

\section{Segment test}

The number of segments $(\mathrm{Ne})$ for blade performance computation was chosen from segment tests. The tests were conducted for NACA 23012 cross-section blades, started from 4 to 20 segments. The blades were equally segmented. The first segment ringswere not included in the computations. In the calculation of rotor performance, the hub or blade extension section at the root section was ignored. Based on the results of the test (Fig. 1), twelve-segmented blades were chosen for performance computing.

Journal of Applied Engineering Science Vol. 18, No. 1, 2020 


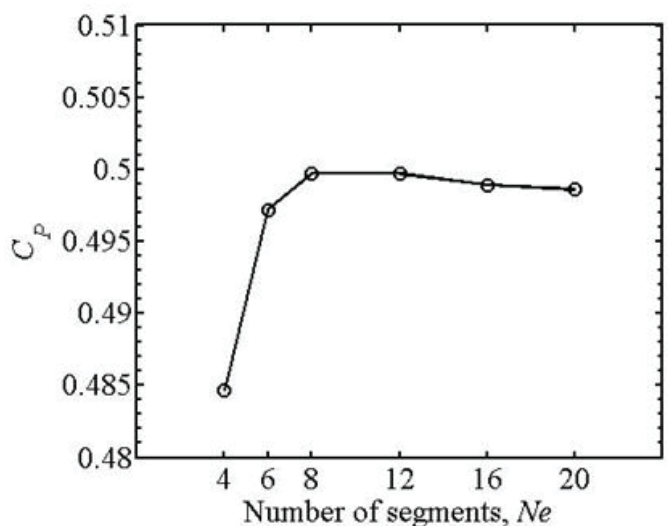

Figure 1: Number of segment test results

\section{RESULTS AND DISCUSSION}

\section{The geometry of the blades}

Figure 2 presented the calculated geometries of rotor designs. Here, we chose normalized rotor geometry representations as chord distribution, twist angle distribution, solidity ratio (solidity factor) distribution, and Reynolds number of blade segments as a function of normalizedspanwise distances.

Chord distributions describe the width of blade segments. The coefficient of lift of blade design $\left(\mathrm{C}_{\mathrm{L}, \mathrm{D}}\right)$ define the length of the blade chord (Eq. 2). The lower the coefficient, the longer the chord. In Fig. 2.a, NACA 0012 cross-section had the widest blade as the results of its lowest $C_{L, D}$. The blade has the highest solidity ratio dis-

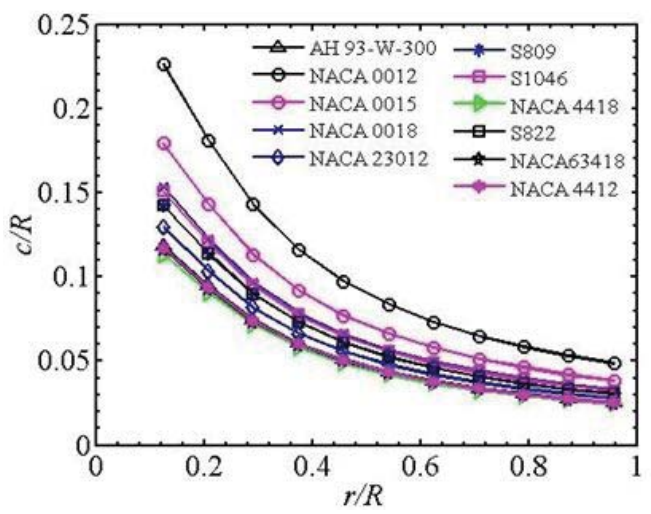

(a) Normalized chord distribution

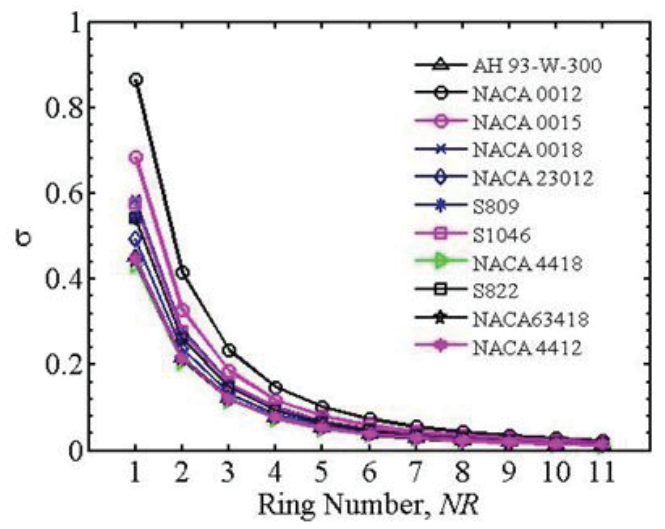

(c) Solidity factor tribution (Fig. 2. c, Eq. 10) and resulted in the highest Reynolds number distribution (Fig. 2.d, Eq. 4).

A higher solidity ratio means the blade needs more amount of materials for construction. Reynolds number is an important parameter that governs the rotor starting easiness. High Reynolds number would produce low viscose force and a low coefficient of drag on a body [19]. A blade that has a high Reynolds number would tend to rotate effort-lesser. In the case of a wind turbine blade, the Reynolds number is calculated using the relative speed and chord length in addition to the air kinematic viscosity parameters. Reynolds number is directly proportional to the relative wind speed and the length of the airfoil chord. The higher the relative wind speed or the greater the length of the chord, the greater the Reynolds number and the greater the torque produced by the blade. The greater the torque produced by the blade, the easier it will rotate.

The problem with small wind turbines is the small Reynolds number so that the torque produced is also small. To maximize the torque produced, the design of the angle of attack which produces the pitch angle of the blade must be precise so that maximum relative wind speed is obtained where the axial interference approaches 1/3. A pitch angle converter mechanism can be added to get the maximum Re when starting at the cut-in wind speed. Modifications to the blade planform can also be done by adding swept or winglet angles to suit the blade design. Figure 2.b showed the twist distribution of the designed

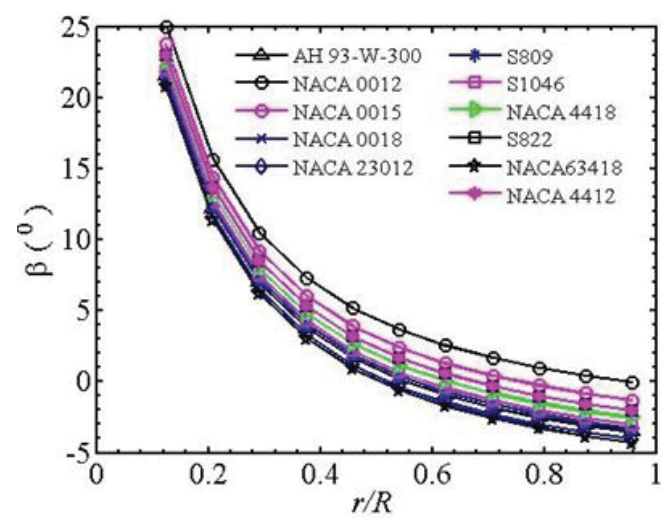

(b) Twist distribution

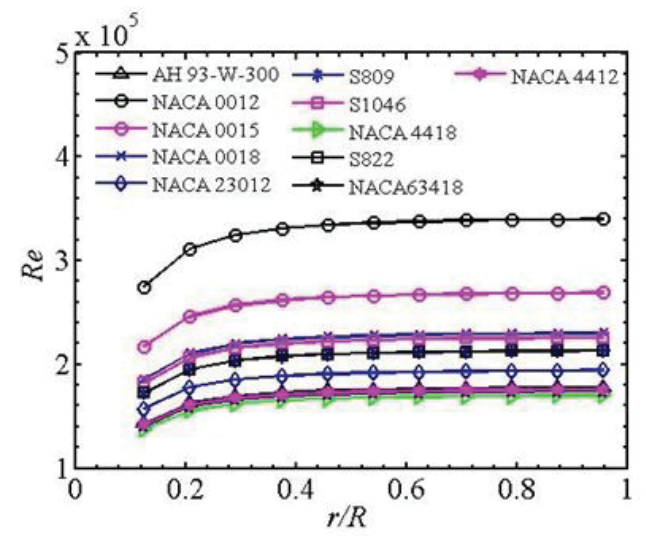

(d) Reynolds number of blade segments

Figure 2: Geometry parameters distribution of rotor blades 
blade. Placement of the twist angle of a rotor blade influenced the flatness of the blade. According to Eq. (3), the designed angle depends on the intended angle of attack $\left(\alpha_{D}\right)$. However, the difference between root twist angle and tip twist angle will be the same for all airfoil. Therefore, the flatness of the designed blade does not depend on $\alpha_{D}$.

\section{Axial and tangential interferences}

The maximum coefficient of power of a wind turbine is $16 / 27$ as stated by Betz. The coefficient is reached when axial interference equals $1 / 3$. A wind turbine rotor blade would have high performance if it can result in axial interference close to the value. Figure 3.a showed the axial interference distributions of the designed blade as a function of normalized spanwise distance. The blade which utilized NACA 63-418 as cross-section resulted in the closest axial interference to $1 / 3$ and blade which applied S822 as cross-section produced the utmost of axial interference distribution.

Schmitz has introduced a tangential interference factor as the rotation of wake included in torque analyzing. The power produced by low $\lambda_{\mathrm{D}}$ (smaller than 4) will be much lower than predicted by Betz as a result of swirl (wake) loss [18], [30]. For $\lambda_{D}$ higher than 4, the Betz power co-

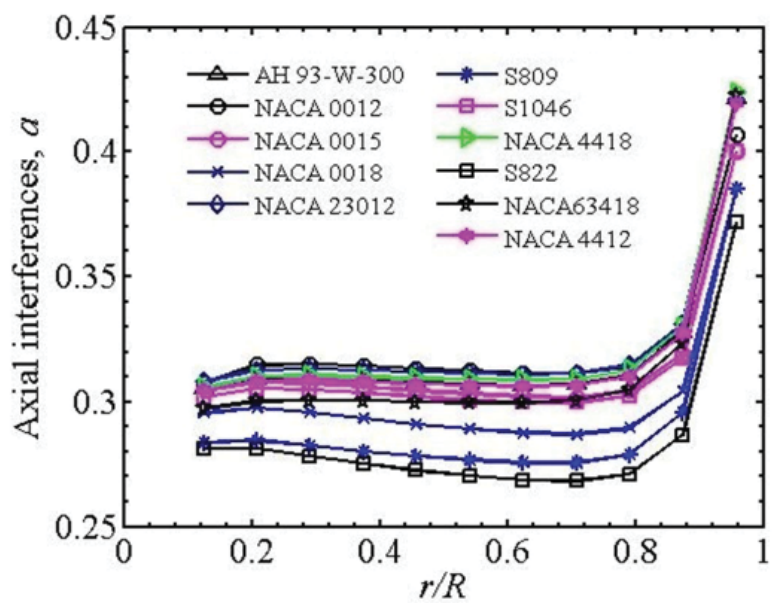

(a) Axial interferences distribution

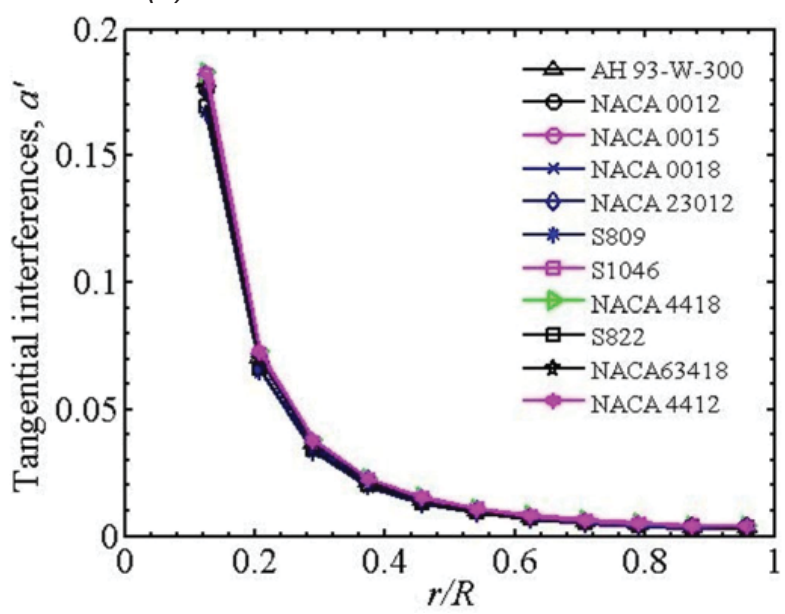

(b) Tangential interferences distribution

Figure 3: Interferences values of rotor blades efficient will be approached [12]. Ideally, a three bladed wind turbine has $\lambda_{D}$ in the range of $5.24-5.45$ [30] and can be pushed to 8 since noise does not become an environmental issue. Figure 3.b described the tangential interference distribution of all designed blades. The figure showed that all the blades developed almost have the same distribution of tangential interference. Therefore, the used airfoil did not affect wake loss.

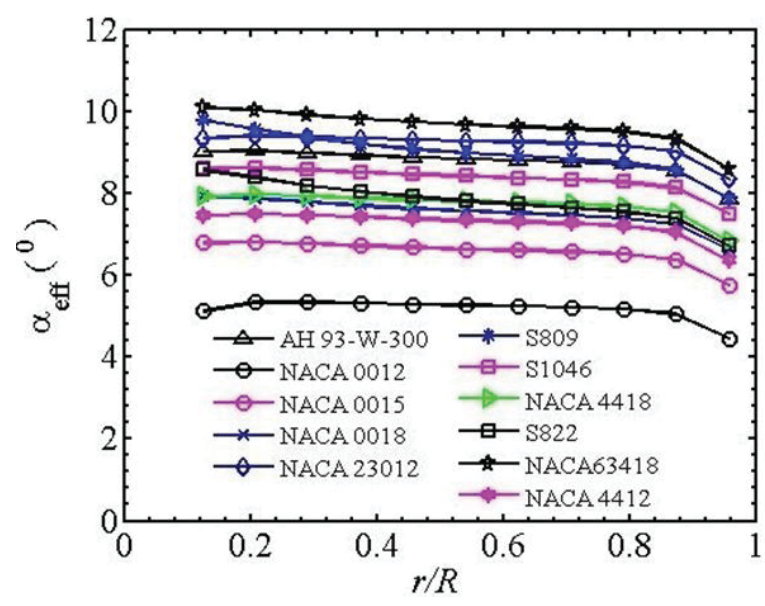

(a) Effective angle of attack distributions

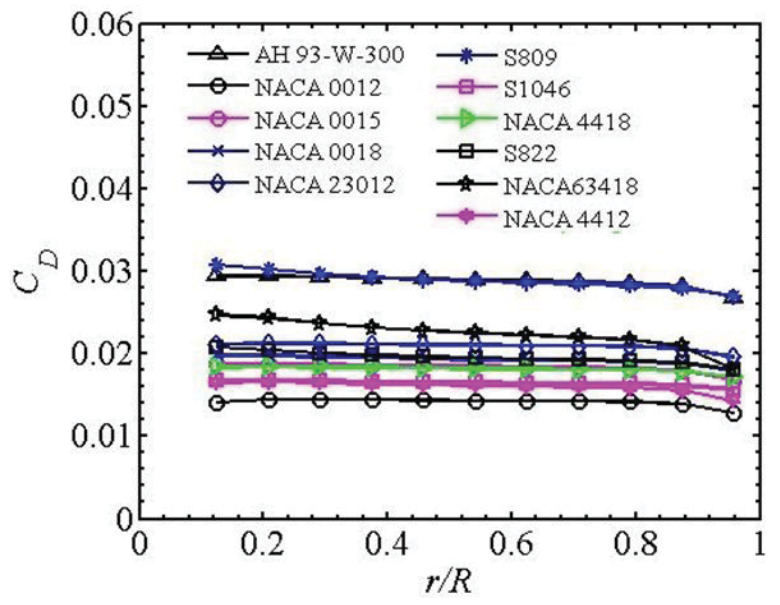

(b) Coefficients of lift distributions

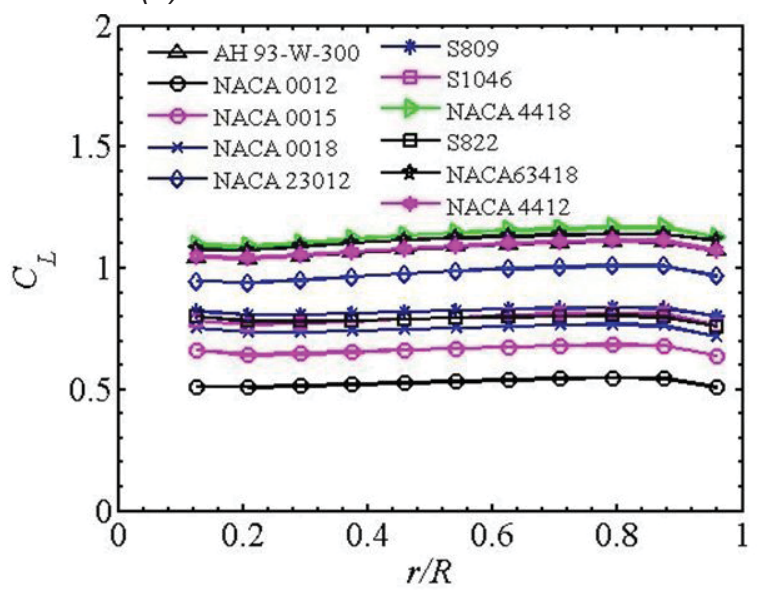

(c) Coefficients of drag distribution

Figure 4: Coefficient of lift and coefficient of drag of the rotors based on the effective angle of attack 


\section{Effective angle of attack, coefficient of lift and drag}

Figure 4. a. shows the distribution of the effective angle of attack $\left(\alpha_{\text {eff }}\right)$ along spanwise. The angles were part of iterative computing results of a and a'. Then, the angels were used to calculate $C_{L}$ and $C_{D}$ distributions as depicted in Fig. 4.a and b. by employing Eq. 1. The computed $\alpha_{\text {eff }} s$ distributions are close to $\alpha_{D} s$, hence the $C_{1}$ distributions come close to $C_{L, D}$. The distribution of $C_{L}$ and $C_{D}$, then, give efficiency near to the maximum airfoil profile efficiency [30].

\section{Power and axial force}

Figure 5 describes the performance computation results of the designed rotor blades. The generated power distributions of each segment were the designed power from a wind speed of $10 \mathrm{~m} \cdot \mathrm{s}^{-1}$ (Fig. 5. a). The blade that utilized NACA 4412 as cross-sections produced the highest power distribution. The airfoil succeeded in converting wind energy into torque better than others. It could build axial interference approaching the ideal value, i.e., 1/3. Airfoil NACA 4418 resulted in almost similar power distribution to NACA 4412 as it had the identical capability in

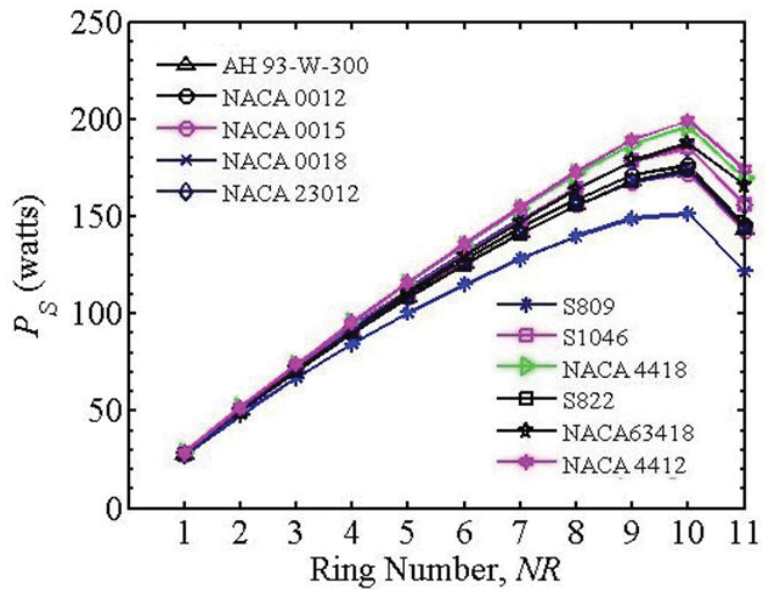

(a) Generated power per segments

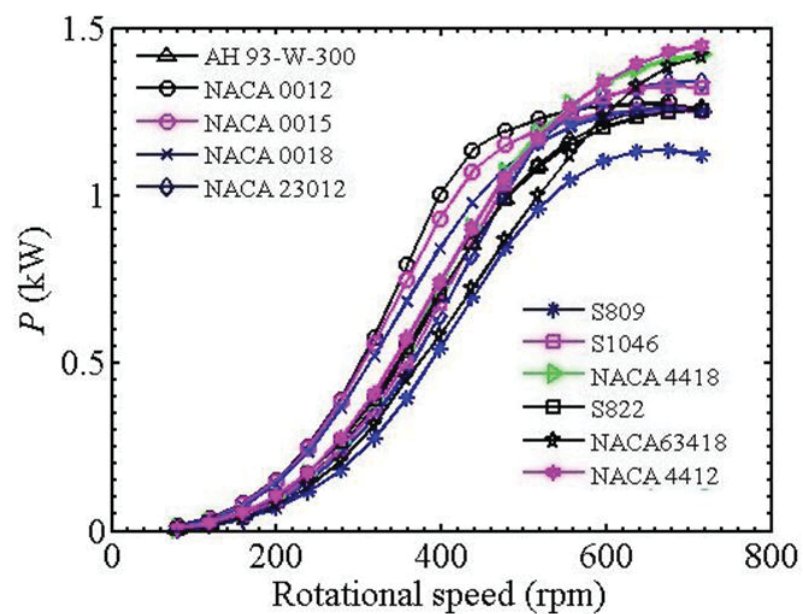

(c) Produced power as rotational speed function at a wind speed of $10 \mathrm{~m} \cdot \mathrm{s}^{-1}$ producing axial interference.Airfoil S809 generated the lowest power distribution. The airfoil yielded higher axial interference than S822. However, S822 more successful in converting wind energy into torque because it had lower $\mathrm{C}_{\mathrm{D}}$ distribution than $\mathrm{S} 809$.

Figure 5.c displays blade power-producing as functions of rotational speeds. At speed design, NACA 4412 generated the highest power. At the starting condition, all airfoil tended to have initial power value. However, with the increasing speed, the generating power grew differently. NACA 0012 made blade had the fastest power development although it did not deliver the highest power at designed speed condition. It was since NACA 0012 yielded the highest chord length distribution (Fig. 2.a) and resulted in the highest Reynolds distribution (Fig. 2.d). Airfoil variation did not affect the designed thrust force of the blades significantly (Fig. 5.b). The generated forces of each segment almost the same. However, the higher chord length distribution delivered the faster development of axial or thrust force (Fig. 5.d). As seen at the blade that used NACA 0012 as cross-sections, the blade had the highest chord distribution (Fig. 2.a). Therefore, it had the fastest thrust development (Fig. 5.b and 5.d).

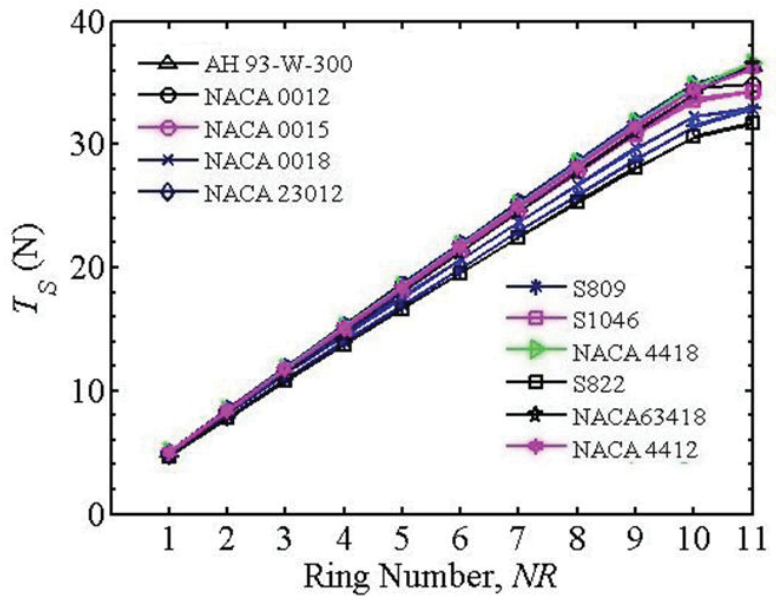

(b) Generated thrust per segment

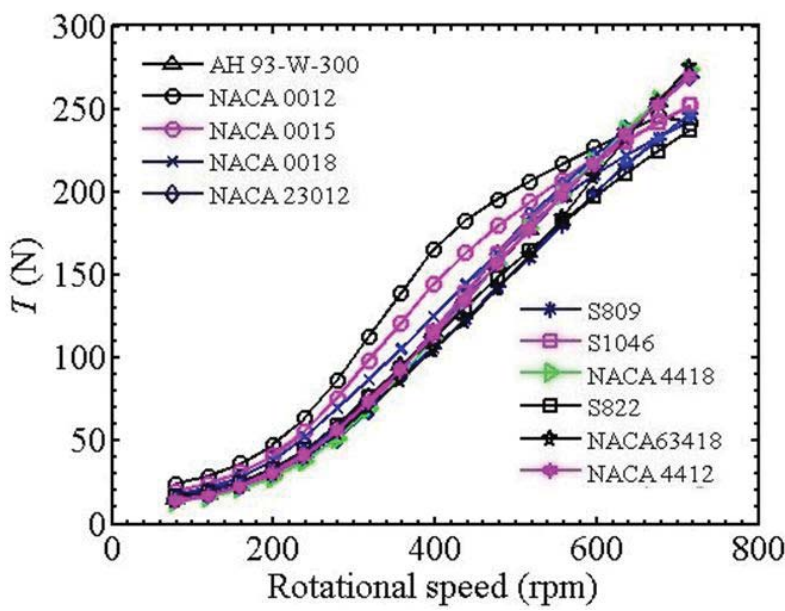

(c) Axial forces as rotational speed function at a wind speed of $10 \mathrm{~m} \cdot \mathrm{s}^{-1}$

Figure 5: Aerodynamic loads of the rotors 


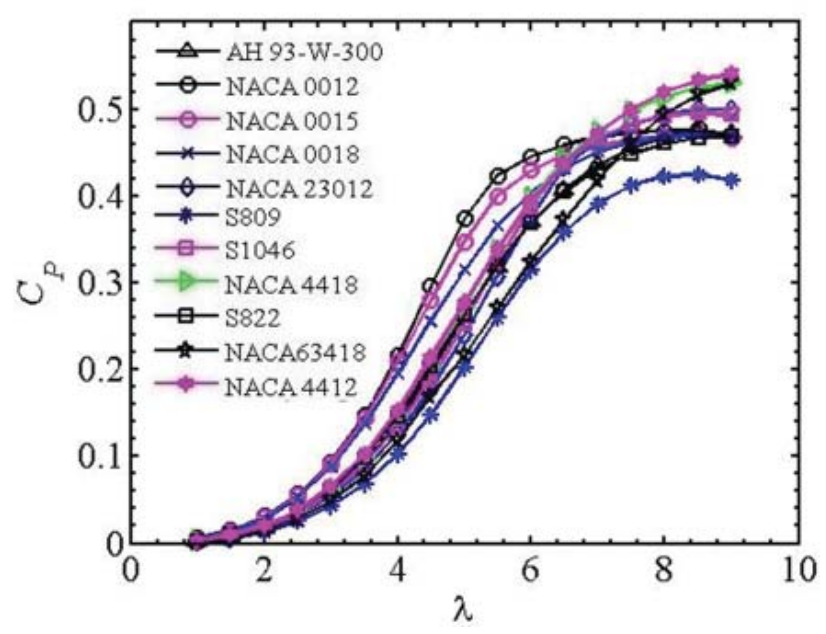

(a) Coefficient of performance as a function of the tip speed ratio

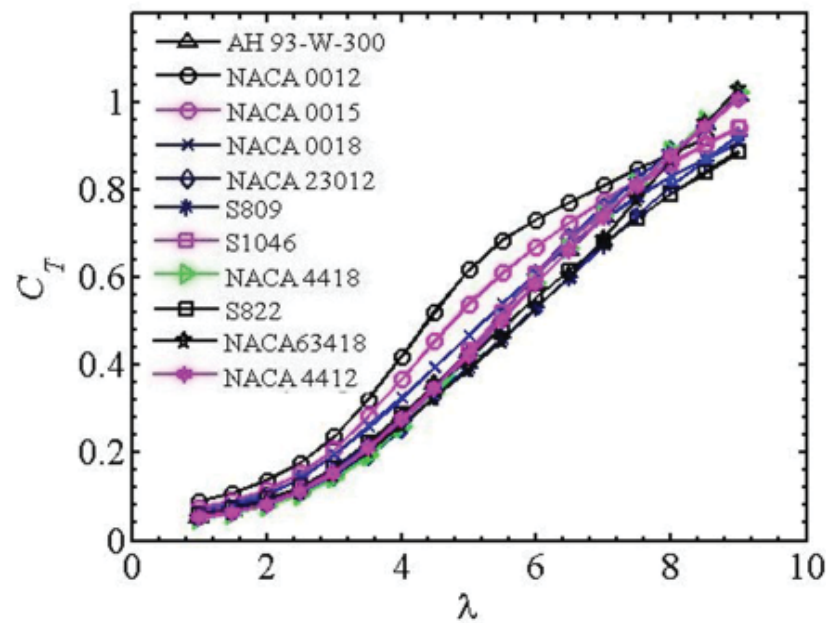

(b) Coefficient of thrust as a function of the tip speed ratio

Figure 6: Performances of the wind turbine rotors

\section{Coefficient of power and coefficient of thrust force}

Figure 6 shows performance in non-dimensional parameters. A higher chord-distribution blade directed to better aerodynamic characteristics. The blade tends to have faster power or coefficient of power growth and more stable from rotational speed changes when it operated in rated condition(Fig. 6.a). However, the design did not underwrite a higher coefficient of performance. The blade also developed a higher thrust than the one that has a shorter chord (Fig. 6.b).

\section{CONCLUSION}

Eleven wind turbine rotors were designed by including eleven different airfoils for the cross-section of the blade of each rotor. The different airfoil of the blades resulted in different planforms and performance. The discussion results are (1) Airfoil that has low $C_{L, D}$ results in high chord distribution along blade span and high Reynolds number of the blade segments. If the airfoil yields low drag coefficient distribution (i.e. NACA 0012), the blade tends to start effortlessly; (2) employing an airfoil in a blade design that has higher lift-coefficient design tend to give smaller chords sizes and solidity ratio. The blade that used the airfoil also tends to have a higher coefficient of power at tip speed ratio design than that has a lower one. But, it could be more sensitive to the changes in its rotational speeds. (3) For a small wind turbine, the coefficient of power of the design $\left(C_{P, D}\right)$ has a low correlation with the solidity ratio of the blade and glide ratio of the utilized airfoil. (4) For a small wind turbine, the coefficient of thrust design $\left(\mathrm{C}_{T}\right)$ has no correlation with the solidity ratio of the blade and glide ratio of the utilized airfoil.

\section{ACKNOWLEDGMENT}

The authors acknowledge LPDP, Ministry of Finance of the Republic of Indonesia, for the fund support of the present work (No. PRJ-4863/LPDP.3/2016).

\section{REFERENCES}

1. Sangston, K., Little, J., Lyall, M.E., Sondergaard, R. (2014). Endwall Loss Reduction of High Lift Low Pressure Turbine Airfoils Using Profile Contouring-Part I: Airfoil Design. Journal of Turbomachinery. vol. 136, no. 8, 081005-1-081005-9, DOI: 10.1115/1.4025952.

2. Wang, Q., Wang, J., Chen, J. et al. (2015). Aerodynamic Shape Optimized Design for Wind Turbine Blade Using New Airfoil Series. Journal of Mechanical Science and Technology. vol. 29, no. 7, 28712882, DOI: 10.1007/s12206-015-0616-X.

3. Shen, X., Yang, H., Chen, J. et al. (2016). Aerodynamic Shape Optimization of Non-straight Small Wind Turbine Blades. Energy Conversion and Management. vol. 119, 266-278, DOI: 10.1016/j.enconman.2016.04.008.

4. Hashem, I., Mohamed, M.H. (2018). Aerodynamic Performance Enhancements of $\mathrm{H}$-rotor Darrieus Wind Turbine. Energy. vol. 142, 531-545, DOI: 10.1016/j.energy.2017.10.036.

5. Chattot, J.J. (2009). Effects of Blade Tip Modifications on Wind Turbine Performance Using Vortex Model. Computers and Fluids. vol. 38, no. 7, 14051410, DOI: 10.1016/j.compfluid.2008.01.022.

6. Numan, M., Kose, F., Ingham, D. et al. (2018). Aerodynamic Performance of a Horizontal Axis Wind Turbine with Forward and Backward Swept Blades. Journal of Wind Engineering \& Industrial Aerodynamics. vol. 176, no. February, 166-173, DOI: 10.1016/j. jweia.2018.03.023.

7. Pavese, C., Kim, T., Murcia, J.P. (2016). Design of a Wind Turbine Swept Blade through Extensive Load Analysis. Renewable Energy. vol. 102, 21-34, DOI: 10.1016/j.renene.2016.10.039.

8. Khamlaj, T.A., Rumpfkeil, M.P. (2017). Theoretical analysis of shrouded horizontal axis wind turbines. Energies. vol. 10, no. 1, 1-19, DOI: 10.3390/ en10010038. 
9. Neammanee, B., Sirisumrannukul, Somporn Chatratana, S. (2010). Control Strategies for Variable-speed Fixed-pitch Wind Turbines. Muyeen SM (ed.), Wind Power. INTECH. pp 209-230.

10. Maheswari, R.U., Tamilvendhan, J. (2012). Analysis of Modelling of Active Stall Controlled and Active Pitch controlled Variable Speed Wind Turbines. International Journal of Modern Engineering Research. vol. 2, no. 4, 2662-2667,

11. Farouk, A., Gawad, A. (2013). New, Simple BladePitch Control Mechanism for Small-Size, Horizontal-Axis Wind Turbines. Journal of Energy and Power Engineering. vol. 7, 2237-2248,

12. Luiz, R., Freitas, U. De, Patrícia, B., Gonçalves, F. (2017). A Revised Theoretical Analysis of Aerodynamic Optimization of Horizontal-Axis Wind Turbines Based on BEM Theory. Renewable Energy. vol. 105, 625-636, DOI: 10.1016/j.renene.2016.12.076.

13. Li, J., Yu, X.B. (2017). Analyses of the Extensible Blade in Improving Wind Energy Production at Sites with Low-Class Wind Resource. Energies. vol. 10, no. 1295, 1-24, DOI: 10.3390/en10091295.

14. Ahmed, N.A. (2013). A Novel Small Scale Efficient Wind Turbine for Power Generation. Renewable Energy. vol. 57, 79-85, DOI: 10.1016/j. renene.2013.01.023.

15. Ma, D., Zhao, Y., Qiao, Y., Li, G. (2015). Effects of Relative Thickness on Aerodynamic Characteristics of Airfoil at A Low Reynolds Number. Chinese Journal of Aeronautics. vol. 28, no. 4, 1003-1015, DOl: 10.1016/j.cja.2015.05.012.

16. Wang, Q., Wang, J., Sun, J. et al. (2016). Optimal Design of Wind Turbine Airfoils Based on Functional Integral and Curvature Smooth Continuous Theory. Aerospace Science and Technology. vol. 55, 34-42, DOI: 10.1016/j.ast.2016.05.004.

17. Schaffarczyk, A.P. (2014). Introduction to Wind Turbine Aerodynamics. doiDOI: 10.1007/978-3-64236409-9

18. Gundtoft, S. (2009). Wind Turbines. University College of Aarhus.

19. Burton, T., Sharpe, D., Jenkins, N., Bossanyi, E. (2001). Wind Energy Handbook. John Wiley \& Sons, Ltd., West Sussex, England.

20. Velázquez, M.T., Vega, M., Carmen, D. et al. (2014). Design and Experimentation of a $1 \mathrm{MW}$ Horizontal Axis Wind Turbine. Journal of Power and Energy Engineering. vol. 2014, no. January, 9-16, DOI: 10.4236/jpee.2014.21002.
21. Hjort, S., Larsen, H. (2015). Rotor Design for Diffuser Augmented Wind Turbines. Energies. vol. 8, no. 10, 10736-10774, DOI: 10.3390/en81010736.

22. Hsiao, F.-B., Bai, C.-J., Chong, W.-T. (2013). The Performance Test of Three Different Horizontal Axis Wind Turbine (HAWT) Blade Shapes Using Experimental and Numerical Methods. Energies. vol. 6, no. 6, 2784-2803, DOI: 10.3390/en6062784.

23. Jensen, M.F., Branner, K. (2013). Introduction to Wind Turbine Blade Design. Brøndsted P, Nijssen RPL (eds.), Advances in Wind Turbine Blade Design and Materials. Woodhead Publishing Limited, Cambridge. pp 1-28.

24. Kaviani, H.R., Nejat, A. (2017). Aerodynamic Noise Prediction of a MW-class HAWT Using Shear Wind Profile Pressure Implicit with Splitting of Operator. Journal of Wind Engineering \& Industrial Aerodynamics. vol. 168, no. June, 164-176, DOI: 10.1016/j. jweia.2017.06.003.

25. Larsen, J.W., Nielsen, S.R.K., Krenk, S. (2007). Dynamic Stall Model for Wind Turbine Airfoils. Journal of Fluids and Structures. vol. 23, 959-982, DOI: 10.1016/j.jfluidstructs.2007.02.005.

26. Li, Q., Maeda, T., Kamada, Y. et al. (2017). Investigation of Power Performance and Wake on a Straight-bladed Vertical Axis Wind Turbine With Field Experiments. Energy. vol. 141, 1113-1123, DOI: 10.1016/j.energy.2017.10.009.

27. Moshfeghi, M., Shams, S., Hur, N. (2017). Aerodynamic Performance Enhancement Analysis of Horizontal Axis Wind Turbines Using a Passive Flow Control Method Via Split Blade. Journal of Wind Engineering and Industrial Aerodynamics. vol. 167, no. May, 148-159, DOI: 10.1016/j.jweia.2017.04.001.

28. Shu, L., Qiu, G., Hu, Q. et al. (2018). Numerical and Field Experimental Investigation of Wind Turbine Dynamic De-icing Process. Journal of Wind Engineering \& Industrial Aerodynamics. vol. 175, no. February, 90-99, DOI: 10.1016/j.jweia.2018.01.043.

29. Biadgo, A.M., Aynekulu, G. (2017). Aerodynamic Design of Horizontal Axis Wind Turbine Blades. FME Transactions (2017). vol. 45, no. 4, 647-660, DOI: 10.5937/fmet1704647m.

30. Ragheb, M., Ragheb, A.M. (2011). Wind Turbines Theory - The Betz Equation and Optimal Rotor Tip Speed Ratio. Carriveau R (ed.), Fundamental and Advanced Topics in Wind Power. InTech. pp 19-38.

Paper submitted: 01.10.2019.

Paper accepted: 09.03.2020.

This is an open access article distributed under the CC $B Y-N C-N D 4.0$ terms and conditions. 